\title{
Akılcı ilaç kullanımı: Varfarin
}

\author{
Rational drug use: Warfarin
}

Vedat Gerdan॰

Çiğli Bölge Eğitim Hastanesi, Romatoloji Kliniği, İzmir, Türkiye

Öz

Varfarin, dünyada trombozun önlenmesi amacıyla çok sayıda endikasyonda ve çok sayıda farklı branşta hekimce en yaygın kullanılan antikoagülandır. Dar bir terapötik indekse sahip olmasının yanı sıra çok sayıda ilaç ve bitki ile ciddi etkileşmeleri de vardır. Her ne kadar yakın zamanda alternatif oral antikoagülan ajanlar geliştirilmiş olsa da bunların antifosfolipid antikor sendromu, sistemik lupus eritematoz gibi romatolojik hastalıklarda etkin ve güvenli olduğuna dair yeterli kanıt yoktur. Bu nedenle varfarin metabolizmasının genetik etkenlerden belirgin etkilendiğini bilmek, yan etkilerini, ilaç ve gıda etkileşmelerini daha iyi tanımak, toksisite ve komplikasyon olduğu zaman hızlı ve doğru karar verebilmenin önemini vurgulamak gerekiyor.

Anahtar Sözcükler: Varfarin, antikoagülan tedavi, endikasyon.

\begin{abstract}
Warfarin is the most widely used anticoagulant by physicians in many indications and in many different branches in order to prevent thrombosis in the world. In addition to having a narrow therapeutic index, it has serious interactions with a large number of medicines and plants. Although alternative oral anticoagulant agents have recently been developed, there is insufficient evidence that they are effective and safe in rheumatologic diseases such as antiphospholipid antibody syndrome and systemic lupus erythematosus. Therefore, it is necessary to know that warfarin metabolism is affected by genetic factors, to recognize side effects, drug and food interactions better, and to emphasize the importance of making fast and accurate decisions when toxicity and complications occur.
\end{abstract}

Keywords: Warfarin, anticoagulant therapy, indication.

\section{Giriş}

Yeni nesil oral antikoagülanlar (NOAC'ler), venöz tromboembolizmde, nonvalvüler atrial fibrilasyonda inme ve sistemik embolizmin önlenmesi gibi geniş bir endikasyon alanında varfarine alternatif olarak sunulmuşsa da henüz romatololojik endikasyonlarda onay almamıştır. Dolayısıyla, varfarin biz romatologlar için hala önemini korumaktadır. Dahası, varfarin dünyada en yaygın kullanılan antikoagülan olup Ingiltere'de yapılan bir çalışmaya göre nüfusun en az $\% 1$ 'i, seksenli yaşlardaki nüfusun ise $\% 8$ ' $i$ tarafından düzenli kullanılmaktadır (1). Ona baktığımızda, tatlı yonca otundan sıçan zehrine ve daha sonra da dünyada en çok kullanılan antikoagülan olmaya uzanan büyüleyici bir hikâye

Sorumlu yazar: Vedat Gerdan

Çiğli Bölge Eğitim Hastanesi, Romatoloji Kliniği, İzmir, Türkiye E-posta:vedatgerdan@gmail.com görürüz. Şu anda yeni oral antikoagülanların ortaya çıkması varfarinin klinik kullanımını gelecekte azaltabilir, ancak bu onun yirminci yüzyılın en büyük buluşlarından biri olduğu gerçeğini değiştirmiyor.

\section{Tarihçe}

1921 yılında ABD'de sığırlarda iç kanamaya bağlı yaygın ölümler görülmüş ve yaklaşık bir yıl içinde ölümlere yedikleri küflü tatlı yoncanın neden olduğu saptanmış. Yaklaşık 20 yıllık bir süreçte yoncadan izole edilen dikumarolun pıhtılaşmada $\mathrm{K}$ vitamininin gerekli olduğu bir basamağı engellediği gösterilmiş ve dikumarol türevlerinden biri "Warfarin" ismi ile fare zehiri olarak onay $\operatorname{almış~(2).~}$ 
Ancak bu ilacın insanlarda kullanımı için ilk dikkat çekici olay, genç bir askerin intihar amacıyla 5 günde toplam $567 \mathrm{mg}$ varfarin fare zehiri kullandığı halde ölmemesi olmuş (3). Kısa bir süre sonra FDA ilacın insanda kullanımını Coumadin $\circledast$ ismiyle onaylamıştır.

\section{Etki mekanizması}

Oral tama yakın emilir, \%99'u albümine bağlı taşınır ve primer olarak sitokrom P450 sistemi yoluyla metabolize edilir. Plazma yarı ömrü 37 saat olup metabolizması ile ilgili izoenzimlerin indüksiyonu veya inhibisyonu INR'yi önemli ölçüde değiştirebilir. Benzer şekilde oral K vitamini tüketimindeki değişiklikler de INR'de önemli dalgalanmalara neden olabilir. Faktör II, VII, IX ve X'un $K$ vitamini aracılı gama karboksilasyonunu inhibe ederek etki gösterir. Bu yolla antikoagülan etkili protein $C$ ve protein S'yi de inhibe eder. Tedavinin ilk günlerinde özellikle faktör II (protrombin) plazmadan temizleninceye kadar (36-72 saat) prokoagülan etki baskın olabileceğinden akut trombotik durumlarda (derin ven trombozu gibi) ilk günlerde parenteral antikoagülanla birlikte kullanılmalıdır (4). Varfarin'in, K vitamini epoksit redüktaz enzim kompleksinin $\mathrm{C} 1$ alt ünitesinin (VKORC1) inhibisyonu yoluyla pıhtılaşma faktörü sentezine müdahale ettiği ve böylece $\mathrm{K} 1$ epoksitinin rejenerasyonunu azalttığı düşünülmektedir. Depresyon derecesi, kısmen hastanın VKORC1 genotipine ve uygulanan dozaja bağlıdır. Terapötik varfarin dozları, karaciğer tarafından yapılan her bir $K$ vitamini bağımlı pıhtılaşma faktörünün aktif formunun toplam miktarını yaklaşık \%30 ila \%50 oranında azaltır (5).

\section{Varfarin doz yanıtını etkileyen faktörler}

\section{A. Hasta ile ilişkili faktörler}

1. Yaș: İleri yaş, artmış varfarin duyarlıı̆̆ı, daha düşük varfarin başlatma ve idame doz gereksinimi ile ilişkili bulunmuştur (6). Bu hassasiyetin mekanizması tam olarak anlaşılmamış ve sıklıkla 80 yaşından büyük hastalar randomize çalışmaların dışında bırakılmıştır (7). Varfarinin farmakokinetiği, ilerleyen yaştan önemli ölçüde etkilenmez (8). Yaşlı hastalarda günde $4-5 \mathrm{mg}$ veya daha düşük dozlarla başlanması, başlatma sırasında supraterapötik INR görülme sıklığını azaltır (9, 10). Amerikan Göğüs Uzmanları Derneği (ACCP) yaşlı hastalarda $5 \mathrm{mg}$ 'ık başlangıç dozlarının kullanılmasını önermektedir (11).
2. Vücut Kitle İndeksi (VKI): Çalışmalarda VKI ile varfarin doz gereksinimi arasında pozitif korelasyon olsa da bu sadece iki çalışmada istatistiksel olarak anlamlı bulunmuştur $(8,12)$. VKI'nin varfarin doz gereksinimine nasıl etki ettiği tam bilinmese de, bunun yaş ve serum albümini üzerinden olması muhtemeldir. Çünkü artan yaşla birlikte serum albümin ve VKİ'nin düştüğü bilinmektedir (8).

3. Beslenme durumu: Düşük $\mathrm{K}$ vitamini deposu olan hastaların, varfarinin farmakodinamik etkilerine, $\mathrm{K}$ vitamini deposu yüksek olanlardan daha duyarlı olduğu gösterilmiştir (13). Varfarin cevabını tahmin etmek için rutin plazma $\mathrm{K}$ vitamini testi önerilmemekle birlikte, yetersiz beslenme, kronik hastalıklarla ilişkili diyetle alımda azalma, uzun süreli parenteral beslenme, gastrointestinal florayı değiştiren antibiyotiklerle tedavi ve yağ malabsorpsiyon sendromları olan hastalara daha düşük varfarin dozları ile başlamanın daha uygun olabileceği unutulmamalıdır. Diyet olarak K vitamini alımında belirgin değişikliklerin bir hafta gibi bir sürede INR'de 1 üniteye varan değişikliğe yol açtığı gösterilmiştir $(14,15)$. $\mathrm{K}$ vitamininden fakir diyetle beslenen hastaların, çok küçük $K$ vitamini alımında bile INR üzerine olan etkileri yönünden çok duyarlı oldukları gösterilmiştir (16). Hastalara, INR yanıtlarında hasta-içi değişkenliği azaltmak için, hastalara diyetlerinde yeterli ve tutarlı bir $\mathrm{K}$ vitamini alımını sürdürmeleri talimatı verilmelidir. Bazı küçük çalışmalar değişken INR'li hastalarda düşük doz $K$ vitamini kullanımından fayda sağlandığını göstermiştir (17-19). Açıklanamayan, dengesiz INR'si olan hastalarda düşük doz oral $K$ vitamini $(100-200 \mathrm{mcg} / \mathrm{g})$ kullanımı için dikkatli bir izlem şartıyla ACCP öneri sunmaktadır (11). K vitamini takviyesine başlarken INR'nin başlangıçta düşmesini önlemek için, INR'nin sıkı monitorizasyonu ve varfarin için ampirik doz artışı gerektiği unutulmamalıdır. Protein depolarının varfarin duyarlılı̆ı üzerindeki etkisinin, azalmış albüminden kaynaklanan protein bağlamadaki değişiklikler nedeniyle olduğu varsayılmaktadır. Yüksek proteinli, düşük karbonhidratlı diyetlerin daha yüksek varfarin doz intiyacı ile ilişkili olduğunu bildiren olgu serileri bildirilmiştir (20, 21). Bu durum serum albümin seviyelerinde veya sitokrom P450 aktivitesinde bir artışa bağlı olabilir. Hastalara, bu tür diyete başlamaları veya bitirmeleri durumunda sıkı izlem gerektiği anlatılmalıdır. 


\section{B. Ko-morbid hastalık durumları}

1. Karaciğer hastalıkları: Neredeyse tüm koagülasyon faktörlerinin sentezlendiği organ olmanın yanı sıra sitokrom P450 üzerinden varfarin metabolizmasında da rol oynar. Kronik karaciğer hastalıklarında $(\mathrm{KKH})$ koagülasyon faktörlerinin ve inhibitörlerinin hemen hepsi azalır $(22,23)$. Bu nedenle varfarin kullanılmasa da INR yüksekliği görülebilir. Bu durum ileri karaciğer hastalığı açısından prognostik bir araç olarak kullanılır (22) ve artan kanama eğilimi ile ilişkilidir (24). Bozulmuş pıhtılaşma ve varfarine artmış duyarlıığı açıklamak için hipoalbüminemi, diyetle alımın azalmasına bağlı K vitamini eksikliği, biliyer obstrüksiyona bağlı $K$ vitamini emilim bozukluğu (24) ve karboksilasyonda K vitaminini kullanma yeteneğinde kazanılmış bir kusur (25) gibi hipotezler ileri sürülmüştür. Pıhtılaşma faktörü ve albümin üretimindeki azalma nedeniyle karaciğer hastalığı olan hastalarda $5 \mathrm{mg}$ gibi düşük bir varfarin dozu ile başlamak gerekir (11). Aynı zamanda özellikle şüpheli veya olası karaciğer hastalığı olanlarda varfarine başlamadan önce özellikle bazal INR'yi kontrol etmek gerekir. Varfarin, neredeyse tamamen sitokrom P450 enzim sistemi yoluyla metabolize olur ve süreç minimal antikoagülan aktiviteli metabolitlerin oluşumu ile sonlanır. Karaciğer hastalığı olan hastalarda varfarin metabolizmasının azalması sonucu supraterapötik INR ve kanama riskinde artış görülür $(26,27)$. Bu nedenle karaciğer hastalığı olan hastalar düşük varfarin dozlarında başlatılmalı ve karaciğer hastalığı olmayan hastalardan daha sık izlenmelidir.

2. Böbrek hastalığı: Varfarin kullanan üremik hastalara hemodiyaliz sırasında kullanılan heparin de kanama riskini artırmaktadır. Gözlemsel çalışmalara göre böbrek hastalarına ayaktan varfarin başlanması artmış majör kanama riski ile ilişkili bulunmuştur $(28,29)$. Retrospektif büyük bir kohort çalışmasından elde edilen verilere göre, hemodiyaliz hastalarında varfarine maruz kalma ile yüksek ölüm oranları arasında bir ilişki ortaya konmuştur (30). Varfarinin hepatik metabolitleri idrarla atılır, çok az varfarin değişmeden atıır. Bu nedenle, kronik böbrek yetmezliği için doz ayarlaması muhtemelen gereksizdir. Bununla birlikte, yeni bir prospektif kohort çalışması, şiddetli böbrek hastalığı $(\mathrm{CrCl}<30 \mathrm{~mL} /$ dak$)$ olan hastaların hafif böbrek yetmezliği olan ( $\mathrm{CrCl}>60 \mathrm{~mL} /$ dak $)$ hastalara göre supraterapötik INR ve kanama sıklığında artış yaşama olasılığının daha yüksek olduğunu göstermiştir (31). Ek olarak, şiddetli böbrek hastalığı olan hastalar, hafif böbrek hastalığı olanlara göre daha düşük varfarin dozuna intiyaç duymuştur. Bu bulgu, böbrek hastalığı olan hastalarda varfarini daha düşük dozda başlatmanın ve INR'yi daha sık izlemenin gerektiğini ortaya koymaktadır.

3. Tiroid hastalıkları: Hipertiroidizm, muhtemelen $\mathrm{K}$ vitaminine bağlı pıhtılaşma faktörlerinin azalması veya protrombin ve faktör VII'nin katabolizmasının artması nedeniyle artan varfarin duyarlıığı ile ilişkilendirilmiştir (32). Vaka raporları, Graves hastalığı olan ve metimazolle tedavi edilen hastaların ötiroid hale geldiklerindeki doza kıyasla, başlangıçta daha düşük doz varfarine intiyaç duyduklarını, metimazol dozundaki dalgalanmaların varfarin yanıtı üzerinde önemli bir etkiye sahip olduğunu göstermiştir $(33,34)$. Hipotiroidi hastalarında, tiroid replasman tedavisinin başlangıcında INR'yi daha sık izlemek önemlidir çünkü normal tiroid fonksiyonlarına ulaşıldığında varfarinde anlamlı doz azalması gerektiğine işaret eden raporlar (32, 35, 36) vardır. Antiaritmik ajanlardan Amiodaron, varfarinin antikoagulan etkisini CYP izoenzim inhibisyonu yoluyla belirgin şekilde artırabilir (37). Bu etkileşim amiodaronun uzun yarı ömrü ve yağ dokusunda birikimi nedeniyle uzun (2-8 hafta kadar) sürebilir. Yeni antiaritmiklerden dronedaron, amiodaronun iodini çıkarılmış, methione-sulfonil grubu eklenmiş hali olup varfarin ile etkileşim bildirilmemiştir (38).

4. Konjestif kalp yetmezliği: Konjestif kalp yetmezliği alevlenmesinin varfarin yanıtına etkisine ait çok az veri olmakla birlikte birkaç çalışmanın regresyon analizinde daha düşük varfarin dozu ile ilişkili bulunmuştur $(27,39,40)$. Bir antikoagülasyon kliniği tarafından ayaktan izlenen hastaların prospektif bir kohort çalışmasından (n:1077) elde edilen kanıtlar, konjestif kalp yetmezliği olup da vitamin $K$ antagonisti alanların hiperkoagülasyon riskinin $(I N R>6)$ kalp yetmezliği olmayan antikoagüle hastalara oranla 1.5 ila 2 kat artmış olduğunu göstermektedir (41). Konjestif kalp yetmezliği öyküsü olan hastalar başlangıçta düşük varfarin dozları almalı, konjestif kalp yetmezliği belirti ve semptomları açısından izlenmeli ve alevlenmeler sırasında INR'leri daha sıkı takip edilmelidir.

5. Akut hastalık durumu: Akut hastalık durumunun varfarin yanıtına etkisi konusunda çok az veri mevcuttur. Prospektif bir kohort 
çalışmasında aşırı anti-koagülasyon $(I N R \geq 6)$ riski (n:300) ishal için rölatif risk $12.8(\% 95 \mathrm{Cl} 1.6-$ 104.9) ateş için ise $2.9(\% 95 \mathrm{Cl} 1.1-7)$ bulunmuştur (42). Başka bir vaka kontrol çalışmasında ateş için OR: 6.018 [\%95 Cl 1.63122.208; $p=.007]$ ) bildirilmiştir (43). Dolayısıyla ishal, ateş veya enfeksiyöz hastalık gibi durumlarda INR değişkenliği olabileceği akılda tutulmalıdır.

6. Cerrahi ve kan kaybı: Özellikle kalp kapağı değiştirme ameliyatından hemen sonraki dönemde değişen varfarin duyarlıı̆ğını bildiren gözlemsel çalışmalar mevcuttur $(44,45)$. Kalp kapak cerrahisi sonrası artmış varfarin duyarlıı̆̆ına neden olabilecek faktörler: Yüksek bazal INR, kardiyopulmoner bypass kaynaklı hemodilüsyon, aşırı sıvı yüklenmesi sonucu geçici hipoalbüminemi ve operasyon sonrası karaciğer konjesyonuna neden olabilen geçici kardiak output azalması sayılabilir. Kardiyopulmoner bypass sonrası serum pıhtılaşma faktörü konsantrasyonlarında öncelikle hemodilüsyon ve kan kaybı nedeniyle geçici bir düşüş gözlenebilir (46). Retrospektif çalışmalardan elde edilen veriler, kalp kapağı ameliyatı geçiren hastaların cerrahi dışı hastalara kıyasla başlangıçta varfarine abartılı bir cevap verebileceğini göstermektedir. Dikkatli izlemle bile, günlük $5 \mathrm{mg}$ ile başlayan hastaların $\% 25$ 'inde antikoagülasyonun başlatılması sırasında INR>4.0 olacaktır. Randomize açık etiketli bir çalışmada kalp kapak cerrahisi sonrası bir grup hastaya sabit $2,5 \mathrm{mg} / \mathrm{g}$, diğer gruba ise standart olan sabit $5 \mathrm{mg} / \mathrm{g}$ varfarin başlanmış. 5 gün INR düzeylerine bakılmış [Kapak operasyonu sonrası erken dönemde istenen INR değeri 2.0 (1.5-2.6 arası). $2.5 \mathrm{mg}$ ile başlanan grupta aşırı antikoagülasyon oranı ve terapötik INR ye ulaşmak için gereken ölçüm sayısı daha az bulunmuştur (47). Her iki grupta da herhangi bir kanama veya tromboembolik komplikasyon görülmemiştir. Varfarin duyarlılığının ameliyattan sonraki 1-3 ayda azaldığı, varfarin dozunda başlangıca göre \% 26-43 arasında bir artış gerekebildiği bildirilmiştir (48). Standart doz ayarlama algoritmaları bu süre zarfında kalp kapakçığı ameliyatı hastalarında etkili olmayabilir. Sonuçta tüm cerrahi prosedürlerden sonra INR'nin dikkatli bir şekilde izlenmesi gerekir.

\section{Ilaç etkileşmeleri}

Varfarin kullanımındaki en önemli sorunlardan biri diğer ilaçlarla potansiyel etkileşimlerin tanınmasıdır. Bu etkileşimler, ilaç tedavisi başlatılı̆ğında veya kesildiğinde farmakokinetik veya farmakodinamik mekanizmalar yoluyla antikoagülanın etkisini değiştirebilir (engelleme veya artırma). Birçok önemli ilaç etkileşimi, CYP2C9 hepatik izoenzimlerinin inhibisyonunu veya endüklenmesini içermekle birlikte CYP3A4 ve CYP1A2 üzerinden de klinik olarak anlamlı etkileşimler bildirilmiştir. Çok sayıda etkileşim olmakla birlikte, varfarinle birlikte kullanılması sakıncalı olan ilaçlar Tablo-1'de listelenmiştir (49).

Tablo-1. Varfarin ile birlikte kullanılmaması gereken ilaçlar.

\begin{tabular}{ll}
\hline Antibiyotikler & Antitrombosit ajanlar \\
\hline Sefaleksin & Aspirin \\
Sefradin & Klopidogrel \\
Sefalosporinler & Aspirin + Klopidogrel \\
Metronidazol & Non steroidal antiinflamatuar ajanlar (NSAID) \\
Kotrimaksasazol & COX-2selektif NSAiD \\
Levofloksasin & Antidepresan ajanlar \\
Norfloksasin & Selektif seratonin reuptake inhibitörleri (SSRI) \\
Amoksisilin & Tramadol \\
Amoksisilin/klavulanik asit & \\
Doksisiklin & \\
Flukanazol & \\
\multicolumn{1}{c}{ PULMONER TROMBOEMBOLiZM TANI VE TEDAVi UZLAŞI RAPORU - 2015'den alınmIştır. } \\
\hline
\end{tabular}


Tablo-2. Koagülasyonu etkileyen bitkiler.

\begin{tabular}{ll}
\hline Grup & Örnekler \\
\hline Kumarin içeren bitkiler & Kereviz, acı ağaç, maydanoz, karahindiba, anason, meyan \\
& kökü, papatya, At kestanesi, bohça otu, çarkıfelek çiçeği, \\
& çemen, dağ kestanesi, frenk inciri, ısırgan otu, kaşıotu, \\
& kırmızı biber, kırmızı yonca, melekotu, melilot, parmakotu, \\
& sinameki, su rezenesi, su yoncası, tatlı yonca, yabani turp, \\
& yabani havuç, yabani kıvırcık salatası, yonca, zargan \\
Antikoagülan özelliği olan bitkiler & Deniz yosunu, kara silcan \\
Salisilat içeren ve/veya antiplatelet özelliklere & Karahindiba, karanfil, yer elması, zencefil, ayakotu, \\
sahip olan bitkiler & demirhindi, fil kulağı, gilobru germisek, Ginseng, \\
& koyungözü, Kaşıkotu, keklik üzümü, meyan kökü, sarımsak, \\
& su yoncası, sinameke, karayılan kökü ekstresi, su reenesi, \\
Fibrinolitik özelliklere sahip olan bitkiler & süt otu, söğüt, toz ağacı, anıt ağacı. \\
Koagülan özelliklere sahip olan bitkiler & Kırmızı biber, sarımsak, soğan, ananas, Ginseng \\
PULMONER TROMBOEMBOLiZM TANI VE TEDAVi UZLAŞı RAPORU - 2015'den alınmıştır.
\end{tabular}

Retrospektif çalışmalarda, çeşitli klinik ortamlarda, varfarin kullanan hastaların \% 5479'una potansiyel olarak etkileşimli bir ilaç verildiği bildirilmiştir (5). Büyük bir retrospektif reçete analizinde klinik olarak anlamlı 25 ilaç-ilaç etkileşiminin prevalansına bakılmış ve yüksek vaka maruz kalma oranının (1000 kişi başına 243 vaka) varfarin ve NSAİ ilaç kombinasyonu reçete edilen kişilerde olduğu görülmüş (50). NSAI ilaçlar veya aspirin farmakodinamik etkileşme ile varfarinin INR üzerindeki etkisini değiştirmeden trombosit fonksiyonunu inhibe ederek kanama riskini arttırma potansiyeline sahiptir. Araştırmalar, reçete yazanların ve eczacıların \%33-50 kadarının ilaç-ilaç etkileşiminin önemli bir kısmını tanıyamadığını gösteriyor $(51,52)$. Bazı bitkisel ilaçlar ve varfarin arasında anlamlı etkileşimlerin varlığını gösteren kanıtlar var, ancak titiz klinik çalışmaların eksikliği bu etkileşimlerin klinik önemini değerlendirmeyi zorlaştırmaktadır. Koagülasyonu etkileyen bitkilerden sık görülenler Tablo-2'de özetlenmiştir (49). Sonuç olarak, hastaya varfarin başlamadan önce hastadan bitkisel, tamamlayıcı ve alternatif ürünlerin kullanımıyla ilgili soruları da içeren bir anamnez alınması ve kullandıkları ürünlerin varfarin ile etkileşime girme, kanama riskini artırma potansiyeli konusunda bilgilendirilmeleri gerekir.

\section{Farmakogenetik ve Etnisite}

1. Farmakogenetik: CYP2C9 ve VKORC1'i kodlayan iki gendeki SNPs klinik faktörlerle birlikte varfarin doz değişkenliğinin en az $\% 50$ 'sinden sorumlu bulunmuştur $(53,54)$.
CYP2C9 daki SNPs (en sık CYP2C9*2 ve CYP2C9*3) yavaş varfarin metabolizması, INR stabilizasyonu için daha uzun bir süre, daha düşük idame dozları, varfarin başlanma döneminde daha yüksek INR ve başlama döneminde olmak üzere kanama riskinde 2-3 kat artış ile ilişkili bulunmuştur $(55,56)$. Sonuç olarak genetik varyantlar varfarin intiyacını önemli derecede etkiler, ancak genotipe dayalı dozaj algoritmaları, bazı spesifik popülasyonlar hariç, rutin kullanımda maliyet-yarar dengesi açısından önerilmiyor (11).

2. Etnisite: Etnisitenin varfarin idame dozunu diğer etmenlerden bağımsız olarak etkilediği gösterilmiştir (57). Aynı çalışmada INR hedefi 2-3 için haftalık ortalama doz Asyalı Amerikalılar için $24 \mathrm{mg}$, Hispanikler için 31 $\mathrm{mg}$, Beyazlar için $36 \mathrm{mg}$ ve Afro-Amerikalılar için $43 \mathrm{mg}$ bulunmuştur. CYP2C9 SNPs artan varfarin duyarlılığı ile ilişkili olsa da Asya kökenli hastalarda bu mutasyonların sıklığı çok düşük olup azalan doz gereksinimlerini açıklamamaktadır $(58,59)$. Asyalılarda düşük varfarin doz intiyacı ile ilişkili VKORC1 haplotipleri, Afro-Amerikalılarda ise daha yüksek varfarin dozlarıyla ilişkili haplotipler yaygındır (60-62). CYP2C9 ve VKORC1'in genetik değişkenliği, Hispanikler için beyazlara kıyasla düşük doz gereksinimlerini açıklayamıyor; henüz bilinmeyen diğer polimorfizmlerden kaynaklanıyor olabilir (63, 64). 


\section{Varfarini nasıl başlayalım?}

Etkili bir antitrombotik ajan olmasına rağmen terapötik aralığı dardır. Doz yanıtındaki geniş varyasyon nedeniyle özellikle başlangıçta dikkatli izlem gerekir. DVT gibi bazı durumlarda terapötik aralığın hızlı bir şekilde sağlanması çok önemli iken ayaktan atrial fibrilasyon gibi durumlarda bu zaman çok önemli olmayabilir. Başlangıç için 10 $\mathrm{mg}, 5 \mathrm{mg}, 2,5 \mathrm{mg}$ ve yaşlılarda $1 \mathrm{mg}$ gibi daha düşük dozlar olabilir. Yüksek başlangıç dozlarında, ilk günlerde görülen prokoagülan aktivite daha yoğun. Crowther ve ark.'ları (65) $5 \mathrm{mg}$ ve $10 \mathrm{mg}$ yükleme dozlarını kıyaslamış, etkinlik olarak anlamlı fark olmamakla beraber $5 \mathrm{mg}$ ile daha az aşırı antikoagülasyon gözlemişlerdir.

\section{Varfarin direnci nedir?}

Herediter varfarin direnci nadir sebeplerden birisi olup bu hastalarda idame dozu diğer bireylere göre 5 kattan 20 kata kadar fazla olabilmektedir. Dirençle ilişkili herediter faktörler: Gastrointestinal sistemden varfarinin emilememesi, varfarin reseptör affinitesindeki değişiklikler, CYP2C9'un normalin çok üstünde aktivite göstermesi ve VKORC1 genindeki mutasyonlar olabilir (66-68). Günlük 15 mg'ın üstündeki doz ihtiyacında varfarin direnci düşünülmelidir. Varfarin direncinin karakteristik özelliği bu hastalarda çok düşük dozlarda $\mathrm{K}$ vitamini ile bile varfarinin etkilerinin hızla nötralize olmasıdır (69).

\section{Kılavuzlara göre varfarin ile farklı durumlarda tedavi yaklaşımları:}

a) CHEST-2012 Antitrombotik tedavi ve trombozun önlenmesi kılavuzuna (70) göre:

1. Ayaktan hastalar için, ilk 2 gün günde $10 \mathrm{mg}$ varfarin ile başlanması ve ardından INR ölçümüne göre doz ayarlaması öneriliyor (Derece 2C).

2. Doz saptanması için rutin farmakogenetik teste karşı öneri (Derece 1B).

3. Akut VTE hastaları için Varfarin tedavisinin (birkaç gün beklemek yerine) heparin tedavisinin 1 . veya 2 . gününde başlatılması öneriliyor (Derece 2C)

4. Varfarin tedavisinde sürekli stabil INR'leri olan hastalar için, 4 haftada bir yerine 12 haftaya kadar aralarla INR ölçümü öneriliyor (Derece 2B).

5. Önceden stabil INR'leri olan, ancak bir kereye mahsus istenen aralıktan 0,5 birimi geçmeyecek derecede artış veya azalma gösteren hastalarda mevcut dozun devamı ve
1-2 hafta içinde INR tekrarı öneriliyor (Derece 2C).

6. Tek bir subterapötik INR değeri ile başvuran stabil terapötik INR'leri olan hastalar için, heparinle (Derece $2 \mathrm{C}$ ) rutin köprü tedavisine karşı öneri

7. VKA ile $K$ vitamini takviyesinin rutin olarak kullanımına karşı̈ öneri (Derece 2C).

8. VKA kullanan hastaların COX-2 selektifler de dahil olmak üzere NSAi ilaçlar ve bazı antibiyotiklerle birlikten kullanımından kaçınılmalı (Derece 2C).

9. Varfarin kullanmakla elde edilecek yararın zarardan daha fazla olduğu, mekanik kapaklı hasta, akut koroner sendrom, yeni koroner stent veya bypass cerrahisi gibi durumlar dışında antiplatelet ajanlarla birlikte kullanımından kaçınııması öneriliyor.

10. Varfarinle tedavi edilen hastalar için INR $<2$ veya INR 3.0-5.0 yerine INR 2.0-3.0 terapötik aralık olarak öneriliyor. (Derece 1B).

11.Önceden arteriyel veya venöz tromboembolizmi olan antifosfolipit sendromlu hastalar için, yüksek yoğunluktan (INR 3.04.5) ziyade orta düzeyde INR aralığına (INR 2.0-3.0) titre edilmiş varfarin tedavisi öneriliyor.

12. Varfarin ile tedaviyi bırakmaya uygun olan hastalar için, dozun kademeli olarak azaltılması yerine aniden kesilmesi öneriliyor (Derece 2C).

13. Varfarin ile INR'leri 4.5 ile 10 arasında olan ve kanama kanıtı olmayan hastalar için, $\mathrm{K}$ vitamini rutin kullanımına karşı öneri. (Derece 2B).

14. Varfarin ile INR $>10.0$ olan ve kanama kanitı olmayan hastalar için oral $\mathrm{K}$ vitamini verilmesi öneriliyor (Derece 2C).

15. Varfarin tedavisini durdurmak için kanama tahmininin tek kriter olarak rutin kullanımına karşı öneri (Derece 2C).

16. Varfarin ile ilişkili majör kanaması olan hastalar için, plazma yerine dört faktörlü konsantre protrombin kompleksi ile antikoagülasyonun hızlı bir şekilde tersine çevrilmesi öneriliyor (Derece 2C).

17. Koagülasyon faktörleri kullanımına (Derece 2C) ek olarak $K$ vitamininin yavaş IV enjeksiyonla uygulanan 5 ila $10 \mathrm{mg}$. kullanımı da öneriliyor (Derece 2C).

b) 2011-BJH varfarin ile oral antikoagülasyon kılavuzuna (71) göre: 


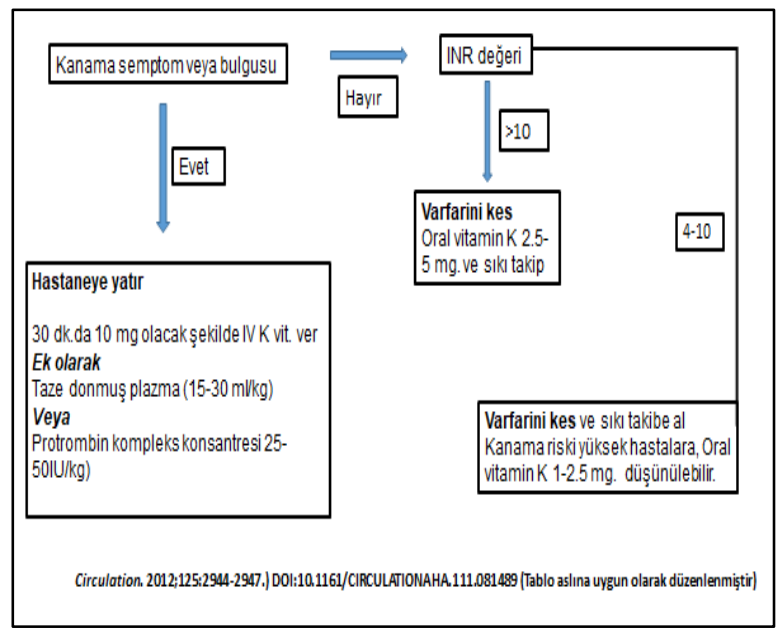

Şekil-1. Varfarin ile INR > 4 olan hastaya yaklaşım algoritması.

i. Varfarin endikasyonları ve önerilen INR değerleri:

a. Venöz Tromboemboli: İlk kez venöz tromboemboli (VTE) geçiren hastada hedef INR 2.5 (1A). VTE tedavisi için varfarin, parenteral antikoagülasyon ile birlikte başlanmalı (1A) ve en az 5 gün, INR de en az 24 saat $\geq 2$ olana kadar (1C) birlikte devam edilmelidir. Antikoagüle iken tekrarlayan VTE durumunda INR hedefi 3.5'a yükseltilmeli $(2 \mathrm{C})$.

b. Antifosfolipid antikorları olan hastalar: Hedef INR $2.5(1 \mathrm{~A})$ olmalıdır.

c. Atrial fibrilasyon (AF): Kardiyak embolinin önlenmesi için AF'li hastalarda INR hedefi 2,5 (1A) olmalı

d. Valvüler kalp hastalığı ve prostetik kapak: Atriyal fibrilasyonu (1A) / sistemik emboli öyküsü $(1 \mathrm{~A}) /$ sol atriyal trombüs $(1 \mathrm{~A})$ veya genişlemiş bir sol atriyumu (2C) olan mitral darlık veya yetmezlikli hastaların INR hedefi 2.5 olmalı.

e. Periferik vasküler hastalık: Sadece intermitant kladikasyosu olan hastalar rutin olarak antikoagüle edilmemelidir (1A). Akut arter embolisi nedeniyle embolektomi yapılan hastalarda INR 2.5 'i hedefleyen uzun süreli antikoagülasyon düşünülmelidir (2C).

f. Miyokart infarktüsü (MI) ve Kardiomiyopati (KMP): MI sonrası kullanılacak ise hedef INR 2.5 (2A). Sistemik emboli proflaksisi için antikoagüle edilecek dilate KMP hastaları için hedef INR 2.5 (2C).

ii. İlk antikoagülasyonun süresi: Proksimal DVT veya $P E$ 'li hastalar en az üç ay boyunca tedavi edilmelidir (1A). İzole baldır veni DVT'sinin tedavisi 6 hafta $(1 \mathrm{~A})$ ile sınırlandırılabilir. Kanserle ilişkili VTE'li hastalar başlangıçta varfarin $(1 A)$ yerine 6 ay süreyle terapötik doz DMAH ile tedavi edilmelidir.

iii. Antikoagülan tedavinin başlatılması: $10 \mathrm{mg}$ yükleme dozunun $5 \mathrm{mg}$ yükleme dozundan üstün olduğunu gösteren bir kanıt yok, ancak yaşlılarda düşük başlangıç dozları veya yaşa göre ayarlanan dozlar ile yüksek INR daha az görülebilir (2B). Genotip guided varfarin başlanmasının standart bir idame dozunu tahmin etmeyi sağlayacak bir doz algoritması geliştirmeye yardımcı olabileceğine dair kanıt yoktur (2B).

iv. Cerrahi ve varfarin: Preoperatif köprü tedavisinde kanama riski düşük, ancak postoperatif kanama riski yüksek cerrahilerden en az 48 saat sonrasına kadar başlatılmaması önerilmektedir (1C). VTE'si üç aydan eski hastalara, köprü tedavisi $(2 \mathrm{C})$ yerine profilaktik doz LMWH. AF riski düşük hastalar (inme /TIA öyküsü yok), köprü tedavisi gerektirmez (2C). Çift yapraklı aort mekanik kapağı olan ve başka risk faktörü olmayan hastalara köprü tedavisi gerekmez (2C). Son üç ay içerisinde VTE'si olan, $\mathrm{AF}$, strok, TIA veya diğer birçok risk faktörünü taşıyan ve mitral mekanik kapaklı hastalara, köprü tedavisi düşünülmeli (2C).

v. Kanamanın ve kanama olmaksızın INR yüksekliğinin tedavisi:

1-Majör kanama: Yaşamı tehdit eden ve 6-8 saat içinde varfarin etkilerinin tamamen geriye döndürülmesi gereken kanamalardır. Tüm hastanelerin eczanesinde lisanslı 4 faktörlü protrombin kompleksi konsantresi (PCC) hazır bulundurulmalıdır (1C). Majör kanamalı hastalarda 25-50 u/kg 4 faktörlü PCC ve $5 \mathrm{mg}$ IV K vitamini kullanılmalı (1B). Bu amaçla rekombinant faktör VIla önerilmez (1B). Taze donmuş plazma, suboptimal etkili; ancak PCC bulunamazsa kullan (1C).

2-Non-majör kanamalar: Varfarin etkisini geri döndürmek için sadece 1-3 mg IV K vitamini önerilir (1B).

3- INR $>5$ ve $>8$ olup kanamayan hastalar: INR $>$ 5.0 olan ancak kanaması olmayan hastalarda 1-2 varfarin atlanmalı, idame dozları azaltılmalı (1B) ve yüksek INR'nin nedeni araştırılmalı (1C). INR> 8.0 olan hastalar $1-5 \mathrm{mg}$ oral $\mathrm{K}$ vitamini (1B) almalıdır.

vi. Varfarin kullanan hastada acil cerrahi: Eğer operasyon 6-12 saat bekleyebilecek ise INR IV K 
vitamini verilerek düzeltilebilir. Ancak bekleyemeyecek durumda ise INR 4 faktörlü $P C C$ ve IV K vit verilerek düzeltilmelidir. PCC acil olmayan, elektif vakalarda kesinlikle kullanılmamalıdır (2C).

vii. Varfarin kullanan hastada kafa travması: Varfarin kullanan hastalar kafa travması ile acile geldiğinde, INR'leri mümkün olan en kısa sürede ölçülmelidir (1C). Varfarin kullanan hastada, kraniyal BT incelemesi için daha düşük bir eşik değeri baz alınmalıdır (2C). Varfarin kullanırken güçlü bir intraserebral kanama şüphesi ile başvuran hastaların, inceleme sonuçlanmaları beklenmeden antikoagülasyonları tersine çevrilmelidir (2C)

viii. Akut VTE sonrası ilk ay INR subterapötik düzeyde ise: VTE sonrası antikoagüle edilmeyen hastada ilk ay rekürrens \%40'tır. Subterapötik INR değeri <1.5 ile <1.7 gibi bir değer kabul edilmektedir. Eğer INR akut bir VTE'nin ilk ayında önemli ölçüde subterapötik hale gelirse, köprüleme tedavisi düşünülebilir $(2 \mathrm{C})$.

ix. Varfarin ve antitrombosit kombinasyonu: Varfarin gerektiğinde, kardiyovasküler hastalığın primer profilaksisi için kullanılan antitrombosit tedavi kesilmelidir (1B). Periferik arter hastalığı veya önceki iskemik inme nedeniyle kullanılan antitrombosit tedavi, varfarin başlandığında kesilmelidir (1B). Stabil iskemik kalp hastalığının sekonder profilaksi için aspirin veya klopidogrel kullanımında (AMI takiben $>12$ ay), varfarin gerekirse bu tedavileri kesilmelidir (2B). Bir Akut koroner sendromdan $<12$ ay sonra, varfarin tedavisi gereken ve tek bir antitrombosit tedavi alan hastalar, yüksek kanama riski taşıdıkları kabul edilmedikçe 12 ayı doldurana kadar birlikte aspirine devam etmelidir (2B). Akut koroner sendrom veya stenti takiben aspirin + klopidogrel kullanan hastada varfarin endikasyonu ortaya çıkarsa, kanama riskini en aza indirmek için üçlü tedavi süresinin minimize edilmesi konusu tartışılmalıdır (2C). Varfarin + tek antitrombosit ajan verileceğinde klopidogrelin aspirine göre kanama riskinin daha yüksek olduğu (100 hasta yılında klopidogrel 12.3, aspirin 5.1) dikkate alınmalıdır (2C).

x. Varfarin kullanırken antitrombosit gereken hasta: Koroner arter stentine intiyaç duyan hastada ilaçı olmayan stent kullanılmalı, sadece 4 hafta üçlü ve ardından 12 ay aspirin + varfarin (2B). Perkutan koroner girişim gerekmeyen hastaya 4 hafta üçlü tedavi, ardından klopidogrel stoplanarak aspirin 11 ay daha devam etmelidir (2C).

xi. Takip önerileri: Bilgisayar destekli dozlama manuel dozlamadan daha iyidir (1A). Varfarin kullanırken öz-kontrol ve öz-yönetim, gelişmiş antikoagülan kontrolüyle ilişkilidir ancak çoğu hasta için uygun olmayabilir (2B). Tüm hastalar, sonuçlar ve doz değişikliklerinin yazıı bir kaydını tutmalıdır (2C). Kararsız INR'li bireylerde, diyeti 100-150 $\mathrm{mg} \mathrm{K}$ vitamini ile desteklemek antikoagülan kontrolünü iyileştirebilir (2B). Varfarin ile etkileşime girebilecek bir ilaç verilen tüm hastalar 3-5 gün sonra (2C) INR yaptırmalıdır.

Tablo-3. Taze donmuş plazma ve Protrombin kompleks konsantresi özelliklerinin karşılaştırılması.

\begin{tabular}{lll}
\hline & $\begin{array}{l}\text { Protrombin Kompleks Konsantresi } \\
\text { (PCC) }\end{array}$ & Taze Donmuş Plazma (TDP) \\
\hline Viral İnaktivasyon & VAR & YOK \\
Uygulanacak Hacim & KÜÇÜK $(20-100 \mathrm{ml})$ & BÜYÜK $(10-30 \mathrm{ml} / \mathrm{kg}$ \\
Kan grubu uygunluğu & HAYIR & EVET \\
Hacim yükleme riski & HAYIR & EVET \\
Transfüzyon İlişkili akut & HAYIR & EVET (\%8-25) \\
akciğer hasarı & & \\
İçerik & Fak II, VII, IX, X içerir ve tam & Elektrolitleri ve tüm faktörleri (fibrinojen \\
Konsantrasyon/IU & replasman sağlar & ve Von Willebrand dahil) içerir \\
Etki zamanı & Stabil & Değişken, F IX<1IU/mL (düşük) \\
Hazırlanma & $10-15 \mathrm{dk}$ & $10-15$ dk, cevap değişebiliyor \\
Yarılanma ömrü & Hızlı & Uzun (çözme ve ısıtma 30 dk) \\
İnfüzyon süresi & $6-8$ saat & $1.5-2$ gün \\
\hline
\end{tabular}




\section{Antifosfolipid Antikor Sendromu (AFS) ve varfarin:}

aFL antikoru ve trombozu (\%76 venöz, \%24 arteriyel) olan 114 hasta 2.5 ve 3.5 hedef INR ye randomize edilerek ortalama $2.7 \mathrm{yll}$ izlenmiş. 2.5 INR hedefli grupta rekürrens 2/58 $(\% 3,4)$ iken diğer grupta 6/56 $(\% 10,7)$ bulunmuş. Venöz tromboz olarak ise 2.5 INR grubunda $1 / 45(\% 2,2)$ diğer grupta $3 / 42(\% 7,1)$ bulunmuştur $(72)$. aFL antikoru ve trombozu (\%60 venöz, \%31 arteriyel, $\% 9$ her ikisi) olan 109 hasta INR 2-3 ve 3-4.5 hedeflerine randomize edilmiş ve ortalama $3.6 \mathrm{yll}$ takip edilmiş. Düşük INR hedefli grupta rekürrens $3 / 52 \quad(\% 5,8)$ iken diğer grupta 6/54 (\%11,1) saptanmıştır (73). 147 hastalık retrospektif çalışmada 3,5 hedef INR 2,5'tan daha uygun bulunmuştur (74). Antifosfolipid antikorları olan hastalarda hedef INR 2.5 (1A) öneriliyor. AFS'lu hastada cerrahi gerektiğinde: Varfarin preop. 4-5 gün önce kesilerek, 12 saatte bir $1 \mathrm{mg} / \mathrm{kg} \mathrm{DMAH}$ (köprü tedavisi) başlanmalı ve operasyon öncesi geceye kadar uygulanmalı. Ortopedik operasyonlarda Varfarin cerrahi gecesinde tekrar başlanabilir ve kontrendikasyon yok ise yanında 12 saatte bir $30 \mathrm{mg}$ DMAH istenen INR ye ulaşana kadar birlikte verilebilir. AFS hastaların epidural ve spinal anestezisinde, epidural ve spinal hematom riskini azaltmak için cerrahi gecesi heparin dozunun atlanması ve kateter çıkarıldıktan sonra olabildiğince erken (optimal 4 saat) başlanması önerilir.

\section{OAK (Varfarin) kullanan hastada dental girişim gerekirse (75):}

Stabil INR'li (2-4 arası) hastada önemli kanama riski çok düşük, ancak OAK geçici olarak kesilen hastalarda tromboz riski artabilir. OAK lar (diş çekimi de dahil) ayaktan hastaların çoğunda kesilmemelidir (Derece A- kanıt düzeyi 1b). Varfarinle stabil INR si (2-4) olan hastalara endokardit profilaksisi için antikoagülan rejimini değiştirmeden tek doz antibiyotik (Derece C, seviye IV). Diş operasyonu geçiren OAK hastalarında kanama riskini azaltmak için: Oksitlenmiş selüloz veya kollajen süngerleri ve sütürlerin kullanımı (Derece $\mathrm{B}$, kanıt düzeyi Illb) \% 5 traneksamik asit gargara, 2 gün, $4 \mathrm{kez} / \mathrm{g}$ (Derece A, kanıt düzeyi lb). Stabil INR'li hastada kontrol INR, 72 saat önce (Derece A, kanıt düzeyi Ib). Varfarin alan hastalara, dental girişim sonrası analjezik olarak non-selektif NSAI ilaçlar ve COX2 inhibitörleri verilmemelidir (Derece $B$, kanıt düzeyi III)

\section{Varfarin Kontrendikasyonları:}

Gebelik, varfarin veya ilacın diğer bileşenlerine karşı bilinen aşırı duyarlık, kanama riskinin muhtemel klinik yarardan fazla olduğu (Hemorajik eğilimler veya kan diskrezileri, yakın zamanda SSS, göz veya geniş travma cerrahisi geçirmiş olmak, GIS, ürogenital yada solunum sisteminde kanama eğilimi yada aktif kanama, serebrovasküler kanama, serebral anevrizma, aort diseksiyonu, perikardit, endokardit gibi durumlarla ilişkili kanama ve kanama eğilimi, düşük tehdidi, eklempsi ve preeklampsi, malign hipertansiyon) durumlar ve denetim altında olmayan demans, alkolizm gibi sorunları olan hastalarda varfarin kullanılmamalıdır.

\section{Varfarin komplikasyonları:}

1) Kanama (ciddi kanama oranı \%1-3): En sık görülen komplikasyonudur. En sık burun, farinks bölgesinde (\%35), daha az sıklıkta yumuşak dokularda (\%21), gastrointestinal sistemde (\%15), üriner sistemde (\%15), seyrek olarak ise intrakranial $(\% 4)$, toraks $(\% 3)$, eklem $(\% 0,5)$ ve retroperitoneumda (\%1) görülebilir.

2) Deri nekrozu, gangren: Küçük kutanöz damarların trombozuna bağlı, primer olarak protein C eksikliği olan hastalarda varfarin başladıktan sonraki 3-8 gün arası dönemde görülebiliyor. Tedavisinde antikoagülan olarak varfarini kesip yerine heparin başlamak ve gerekiyorsa yara debritmanı yapmak uygun olur.

3) Mor ayak (purple toe) sendromu: Varfarinin nadir bir komplikasyonu olup en sık sebep olarak kolesterol embolisi gösterilmektedir. Varfarin başlandıktan 3-8 hafta içinde hastada mor ayak görülürse akla gelmelidir. Erken yakalanırsa tamamen geri dönüşümlü olup varfarini kesip alternatif antikoagülanlara geçmek gerekir.

\section{Varfarin zehirlenmesi ve tedavi yaklaşımları:}

Acil servise varfarin kullanırken başvuran hastalar toksisite yönünden asemptomatik olabileceği gibi, farklı sistemlere ait kanama bulgusu da olabilir. Bu nedenle, dikkatli bir fizik muayene ve anamnez çok önemlidir. Fizik muayene sırasında epistaksis, hematüri, hipermenore, diş eti kanamaları, cilt altı ekimozlar, intrakranial kanamaya bağlı nörolojik semptomlar dikkatle aranmalıdır. Gastrointestinal kanamalar açısından alınan ilk hemogramdaki hemoglobin değerinin yanıltıcı olabileceği akılda tutulmalı ve hemogram takibi gerekliliği unutulmamalıdır. 
Sonuç olarak: Varfarin çok sayıda branşta hekim tarafından trombozların profilaksi ve tedavisinde sıkça kullanılan bir ajandır. Her ne kadar alternatif oral antikoagülan ajanlar geliştirilmiş olsa da bunların antifosfolipit antikor sendromu, sistemik lupus eritamatoz gibi romatolojik hastalıklarda etkin ve güvenli olduğuna dair yeterli kanıt yoktur. Bu nedenle varfarin metabolizmasının genetik etkenlerden belirgin etkilendiğini bilmek, yan etkilerini, ilaç ve gıda etkileşmelerini daha iyi tanımak, toksisite ve komplikasyonlarda hızlı ve doğru karar verebilmenin önemini vurgulamak gerekiyor.

\section{Kaynaklar}

1. Pirmohamed M. Warfarin: almost 60 years old and still causing problems. Br J Clin Pharmacol 2006; 62 (5): 509-11.

2. Ramachandran S, Pitchai S. Story of warfarin: From rat poison to lifesaving drug. Indian J Vasc Endovasc Surg 2018; 5: 174-5.

3. Shapiro SS. Treating thrombosis in the 21st century. N Engl J Med [editorial] 2003; 349 (18): 1762-4.

4. Hirsh J, Dalen J, Anderson DR, et al. Oral anticoagulants: mechanism of action, clinical effectiveness, and optimal therapeutic range. Chest 2001; 119 (1 Suppl): 8S-21S.

5. White PJ. Patient factors that influence warfarin dose response. J Pharm Pract 2010; 23 (3): 194-204.

6. James $A H$, Britt RP, Raskino CL, et al. Factors affecting the maintenance dose of warfarin. J Clin Pathol 1992; 45 (8): 704-706.

7. Hylek EM. Oral anticoagulants pharmacologic issues for use in elderly. Clin Geriatr Med 2001; 17 (1): 1-13.

8. Singla DA, Morrill GB. Warfarin maintenance dosages in the very elderly. Am J Health Syst Pharm $2005 ; 62$ (10): 1062-6.

9. Siguret V, Gouin I, Debray M, et al. Initiation of warfarin therapy in elderly medical inpatients: A safe and accurate regimen. Am J Med 2005; 118 (2): 137-42.

10. O'Connell MB, Kowal PR, Allivato CJ, et al. Evaluation of warfarin initiation regimens in elderly inpatients. Pharmacotherapy. 2000; 20 (8): 923-930.

11. Ansell J, Hirsh J, Hylek E, et al. Pharmacology and management of the vitamin $\mathrm{K}$ antagonists. Chest 2008;133(6 suppl): 160S-198S

12. Absher RK, Moore ME, Parker MH. Patient-specific factors predictive of warfarin dosage requirements. Ann Pharmacother 2002; 36 (10): 1512-7.

13. Cushman M, Booth SL, Possidente CL, et al. The association of vitamin $\mathrm{K}$ status with warfarin sensitivity at the onset of treatment. Br J Haematol 2001; 112 (3): 572-7.

14. Couris $\mathrm{R}$, Tataronis $\mathrm{G}$, McCloskey $\mathrm{W}$, et al. Dietary vitamin $\mathrm{K}$ variability affects international normalized ratio (INR) coagulation indices. Int J Vitam Nutr Res 2006; 76 (2): 65-74.

15. Franco V, Polanczyk CA, Clausell N, et al. Role of dietary vitamin K intake in chronic oral anticoagulation: prospective evidence from observational and randomized protocols. Am J Med 2004; 116 (10): 651-6.

16. Kurnick D, Loebstein R, Rabinovitz H, Austerweil N, Halkin H, Almog S. Over-the-counter vitamin K1containing multivitamin supplements disrupt warfarin anticoagulation in vitamin $\mathrm{K} 1$-depleted patients. Thromb Haemost 2004; 92 (5): 1018-24.

17. Sconce E, Avery P, Wynne H, et al. Vitamin K supplementation can improve stability of anticoagulation for patients with unexplained variability in response to warfarin. Blood 2007; 109 (6): 2419-23.

18. Reese AM, Farnett LE, Lyons $\mathrm{R}$, et al. Low-dose vitamin $\mathrm{K}$ to augment anticoagulation control. Pharmacotherapy 2005; 25 (12): 1746-51.

19. Ford SK, Misita CP, Shilliday BB, et al. Prospective study of supplemental vitamin K therapy in patients on oral anticoagulants with unstable international normalized ratios. J Thromb Thrombolysis 2007; 24 (1): 23-7.

20. Beatty SJ, Mehta BM, Rodis JL. Decreased warfarin effect after initiation of high-protein, low-carbohydrate diets. Ann Pharmacother 2005; 39 (4): 744-7.

21. Hornsby LB, Hester EK, Donaldson AR. Potential interaction between warfarin and high dietary protein intake. Pharmacotherapy 2008; 28 (4): 536-9. 
22. Deitcher SR. Interpretation of the international normalised ratio in patients with liver disease. Lancet 2002; 359 (9300):47-8.

23. Kovacs MJ, Wong A, MacKinnon K, et al. Assessment of the variability of the INR system for patients with liver impairment. Thromb Haemost 1994; 71 (6): 727-30.

24. Kujovich JL. Hemostatic defects in end stage liver disease. Crit Care Clin 2005; 21 (3): 563-87.

25. Blanchard RA, Furie BC, Jorgensen M, et al. Acquired vitamin K-dependent carboxylation deficiency in liver disease. N Engl J Med 1981; 305 (5):242-8.

26. Brigden ML, Kay C, Le A, et al. Audit of the frequency and clinical response to excessive oral anticoagulation in an out-patient population. Am J Hematol 1998; 59 (1): 22-7.

27.Zhang K, Young C, Berger J. Administrative claims analysis of the relationship between warfarin use and risk of hemorrhage including drug-drug and drug-disease interactions. J Manag Care Pharm 2006;12(8):640-8.

28. Landefeld CS, Goldman OL. Major bleeding in outpatients treated with warfarin: incidence and prediction by factors known at the start of outpatient therapy. Am J Med 1989; 87 (2): 144-52.

29. Beyth RJ, Quinn LM, Landefeld CS. Prospective evaluation of an index for predicting the risk of major bleeding in outpatients treated with warfarin. Am J Med 1998; 105 (2): 91-9.

30.Chan KE, Lazarus JM, Thadhani R, et al. Anticoagulant and antiplatelet usage associates with mortality among hemodialysis patients. J Am Soc Nephrol 2009; 20 (4): 872-81.

31.Limdi NA, Beasley M, Baird MF, et al. Kidney function influences warfarin responsiveness and hemorrhagic complications. J Am Soc Nephrol 2009; 20 (4): 912-21.

32. Demirkan K, Stephens MA, Newman KP, et al. Response to warfarin and other oral anticoagulants: effects of disease states. South Med J 2000; 93 (5): 448-54.

33. Akin F, Yaylali GF, Bastemir M, et al. Effect of methimazole on warfarin anticoagulation in a case of Graves' disease. Blood Coagul Fibrinolysis 2008; 19 (1): 89-91.

34.Busenbark LA, Cushnie SA. Effect of Graves' disease and methimazole on warfarin anticoagulation. Ann Pharmacother 2006; 40 (6): 1200-3.

35. Stephens MA, Self TH, Lancaster D, et al. Hypothyroidism: effect on warfarin anticoagulation. South Med J 1989; 82 (12): 1585-6.

36. Bucerius J, Joe AY, Palmedo H, Reinhardt MJ, Biersack HJ. Impact of short-term hypothyroidism on systemic anticoagulation in patients with thyroid cancer and coumarin therapy. Thyroid 2006; 16 (4): 369-74.

37. Heimark LD, Wienkers L, Kunze K, et al. The mechanism of the interaction between amiodarone and warfarin in humans. Clin Pharmacol Ther 1992; 51 (4): 398-407.

38. Patel C, Yan GX, Kowey PR. Dronedarone. Circulation 2009; 120 (7): 636-44.

39. Garcia D, Regan S, Crowther M, Hughes RA, Hylek EM. Warfarin maintenance dosing patterns in clinical practice. Chest 2005; 127 (6): 2049-56.

40. Whitely HP, Fermo JD, Chumney EC, Brzezinski WA. Effect of patient-specific factors on weekly warfarin dose. Ther Clin Risk Manag 2007; 3 (3): 499-504.

41. Visser LE, Bleumink GS, Trienekens PH, Vulto AG, Hofman A, Stricker BH. The risk of overanticoagulation in patients with heart failure on coumarin anticoagulants. Br J Haematol 2004; 127 (1): 85-9.

42. Penning-van Beest FJ, van Meegen E, Rosendaal FR. Characteristics of anticoagulant therapy and comorbidity related to overanticoagulation. Thromb Haemost 2001; 86 (2): 569-74.

43. Cadiou G, Varin R, Levesque $\mathrm{H}$, et al. Risk factors of vitamin $\mathrm{K}$ antagonist overanticoagulation: A case-control study in unselected patients referred to an emergency department. Thromb Haemost 2008; 100 (4): 685-92.

44. Schulman S, El Bouazzaoui B, Eikelboom JW, Zondag M. Clinical factors influencing the sensitivity to warfarin when restarted after surgery. J Intern Med 2008; 263 (4): 412-9.

45. Lee J, Lee B, Kim K, et al. Factors affecting warfarin therapy following cardiac valve surgery. Ann Pharmacother 2002; 36 (12): 1845-50.

46. Chandler WL. Effect of hemodilution, blood loss, and consumption on hemostatic factor levels during cardiopulmonary bypass. J Cardiothorac Vasc Anesth 2005; 19 (4): 459-67. 
47. Ageno W, Turpie AGG, Steidl L, et al. Comparison of a Daily fixed $2.5 \mathrm{mg}$ warfarin dose with a $5 \mathrm{mg}$, international normalized ratio adjusted, warfarin dose initially following heart valve replacement. Am J Cardiol 2001; 88 (1): 40-4.

48. Lenzini PA, Grice GR, Milligan PE, et al. Optimal initial dose adjustment of warfarin in orthopedic patients. Ann Pharmacother 2007; 41 (11): 1798-804.

49. Antikoagülan Tedavi. Toraks Derneği Pulmoner Tromboembolizm Tanı ve Tedavi Uzlaşı Raporu 2015. 34-40. toraks.org.tr.

50. Malone DC, Hutchins DS, Haupert $\mathrm{H}$, et al. Assessment of potential drug-drug interations with a prescription claims database. Am J Health Syst Pharm 2005; 62 (19): 1983-91.

51. Glassman PA, Simon B, Belperio P, Lanto A. Improving recognition of drug interactions: benefits and barriers to using automatic drug alerts. Med Care 2002; 40 (12): 1161-71.

52. Weideman RA, Bernstein IH, McKinney WP. Pharmacist recognition of potential drug interactions. Am J Health-Syst Pharm 1999; 56 (15): 1524-9.

53. Wadelius M, Chen LY, Downes K, et al. Common VKORC1 and GGCX polymorphisms associated with warfarin dose. Pharmacogenomics J 2005; 5 (4): 262-70.

54.Sconce EA, Khan TI, Wynne HA, et al. The impact of CYP2C9 and VKORC1 genetic polymorphism and patient characteristics upon warfarin dose requirements: proposal for a new dosing regimen. Blood 2005; 106 (7): 2329-33.

55. Aithal GP, Day CP, Kesteven PJ, Daly AK. Association of polymorphisms in the cytochrome P450 CYP2C9 with warfarin döşe requirement and risk of bleeding complications. Lancet 1999; 353 (9154): 717-9.

56. Higashi MK, Veenstra DL, Kondo LM, et al. Association between CYP2C9 genetic variants and anticoagulation-related outcomes during warfarin therapy. JAMA 2002; 287 (13): 1690-8.

57. Dang MT, Hambleton J, Kayser SR. The influence of ethnicity on warfarin dosage requirement. Ann Pharmacother 2005; 39 (6): 1008-12.

58. Gage BF, Lesko LJ. Pharmacogenetics of warfarin: regulatory, scientific, and clinical issues. J Thromb Thrombolysis 2008; 25 (1): 45-51.

59. National Heart, Lung, and Blood Institute. Clarification of optimal anticoagulation through genetics (COAG). Clinical Trials.gov http://clinicaltrials.gov/ct2/show/NCT00839657

60. Rieder MJ, Reiner AP, Gage BF, et al. Effect of VKORC1 haplotypes on transcriptional regulation and warfarin dose. N Engl J Med 2005; 352 (22): 2285-93.

61.Limdi NA, Beasley TM, Crowley MR, et al. VKORC1 polymorphisms, haplotypes and haplotype groups on warfarin dose among African-Americans and European-Americans. Pharmacogenomics 2008;9(10):1445-58.

62. Schwartz UI, Ritchie MD, Bradford Y, et al. Genetic determinants of response to warfarin during initial anticoagulation. N Engl J Med 2008; 358 (10): 999-1008.

63. Dang MT, Hambleton J, Kayser SR. The influence of ethnicity on warfarin dosage requirement. Ann Pharmacother 2005; 39 (6): 1008-112.

64. Marsh S, King CR, Porche-Sorbet RM, Scott-Horton TJ, Eby CS. Population variation in VKORC1 haplotype structure. J Thromb Haemost 2006; 4 (2): 473-4.

65. Crowther MA, Ginsberg JB, Kearon C, et al. A randomized trial comparing 5-mg and 10-mg warfarin loading doses. Arch Intern Med 1999; 159 (1):46-8.

66. Alving BM, Strickler MP, Knight RD, Barr CF, Berenberg JL, Peck CC. Hereditary warfarin resistance. Investigation of a rare phenomenon. Arch Intern Med 1985; 145: 499-501.

67. Bodin L, Perdu J, Diry M, Horellou MH, Loriot MA. Multiple genetic alterations in vitamin K epoxide reductase complex subunit 1 gene (VKORC1) can explain the high dose requirement during oral anticoagulation in humans. J Thromb Haemost 2008; 6: 1436-9.

68. Schmeits PC, Hermans MH, van Geest-Daalderop JH, Poodt J, de Sauvage Nolting PR, Conemans JM. VKORC1 mutations in patients with partial resistance to phenprocoumon. $\mathrm{Br} \mathrm{J}$ Haematol 2010; 148: 955-7.

69. Linder MW. Genetic mechanisms for hypersensitivity and resistance to the anticoagulant Warfarin. Clin Chim Acta 2001 ; 308: 9-15. 
70. Holbrook A, Schulman S, Witt DM, at al. Evidence-based management of anticoagulant therapy: Antithrombotic Therapy and Prevention of Thrombosis, 9th ed: American College of Chest Physicians Evidence-Based Clinical Practice Guidelines. Chest 2012; 141 (2 Suppl):e152S-e184S. doi: 10.1378/chest.112295.

71. Keeling D, Baglin T, Tait C et al. Guidelines on oral anticoagulation with warfarin - fourth edition. Br $\mathrm{J}$ Haematol 2011; 154 (3): 311-24.

72. Mark A, Ginsberg JS, Julian J et al. A comparison of two intensities of warfarin for the prevention of recurrent thrombosis in patients with the antiphospholipid antibody syndrome. N Engl J Med 2003; 349:1133-8.

73. Finazzi G, Marchioli R, Brancaccio V, et al. A randomized clinical trial of high-intensity warfarin vs. conventional antithrombotic therapy for the prevention of recurrent thrombosis in patients with the antiphospholipid syndrome (WAPS). J Thromb Haemost 2005; 3 (5): 848-53.

74. Khamashta MA, Cuadrado MJ, Mujic F, Taub NA, Hunt BJ, Hughes GR. The management of thrombosis in the antiphospholipid-antibody syndrome. N Engl J Med 1995; 332: 993-7.

75. Perry D, Noakes T, Helliwell P; British Dental Society. Guidelines for the management of patients on oral anticoagulants requiring dental surgery. Br Dent J 2007; 203 (7): 389-93. 